\title{
Psychic Cognitive Processes Development at Primary School Age
}

\author{
Almakhan Kabylova, Manshuk Kussainova \\ Department of Pedagogy, Institute of Advanced Training for Teachers, Aktau City, Kazakhstan \\ Email: manshuk61@mail.ru
}

Received 4 March 2014; revised 1 April 2014; accepted 28 April 2014

Copyright (C) 2014 by authors and Scientific Research Publishing Inc.

This work is licensed under the Creative Commons Attribution International License (CC BY). http://creativecommons.org/licenses/by/4.0/

(c) (i) Open Access

\section{Abstract}

This paper describes the program of cognitive processes development for $\mathbf{2}^{\text {nd }}$ grade schoolchildren, designed and implemented at a secondary school in Aktau City (Kazakhstan). The program of cognitive processes development was designed for the $2^{\text {nd }}$ grade schoolchildren. Second grade is the optimal to conduct correction development classes. Most part of the program consisted of exercises, games, techniques to develop memory, attention, verbal-logical thinking of children. The program supposed group work ( 7 - 10 people) twice a week for about 30 - 35 minutes before midday. Every game was "repeated" several times on different materials during several classes. Correction-development activity took 4 months. The third stage of realization of developing program was in conducting second check-up on offered before diagnostics methods. This allowed the researcher to determine how efficient was offered and approved program on cognitive processes development with primary school children development. Conducted research allowed stating that designed and approved program on the development of cognitive processes was efficient.

\section{Keywords}

Cognitive Processes Development, Memory Development, Personality Development, Cognitive Area Development and Correction

\section{Introduction}

One of the most important trends of school psychologist work with primary school children is cognitive area development. Development work with each of cognitive processes has its own specificity. Thus on the basis of correction of visual-image thinking at school age are revelation and reflection of objective links and relationship of the reality in the form of visual-space models. The basic objective of development and correction in this case is the formation of the child's skill to create and use significant symbolic means of cognitive tasks solution. 
Herewith children orientation should be directed at general ways of activity and not only specific result acquisition. It is reasonable to use such ways of constructive activity as construction according to the sample, conditions and intention. Memory development correction can be directed at formation of general structure of mnemonic activity of the child, i.e. distinguishing of special objectives of memorizing and reproduction of the past experience and also formation of external mediation. Memory development correction is determined by the objectives of formation of the child's skills to control his activity. Cognitive area development and correction should be done in the context of both education and game activity.

One of the key statements of cultural-historic development by L.S. Vygotskiy is statement about active role of a person in environment discovery. According to L.S. Vygotskiy, development process is self-advancement of the subject owing to his activity with objects and facts of heredity and environment are only conditions that determine not the gist of development process but different variations within the norm (Vygotskiy, 1983).

L.S. Vygotskiy intentionally underlined that "the basis of upbringing process is learner's personal activity and all the skill of the teacher is to direct and regulate this activity. It is more important to teach the child to think, thus to inform him of some knowledge (Vygotskiy, 1984).

This idea was supported and developed by L.S. Vygotskiy's successors. Thus, according to D.B. Elkonin "no adult influence on psychic development processes can be done without real activity of the child himself" (Elkonin, 1974).

According to A.N. Leontyev, child's education and upbringing are nothing else than a special kind of assumption and reproduction by him socially and historically predetermined abilities. The researcher pointed out that culture as a general source of the child's psychic development functions only when the child completes an activity, directed at social abilities assumption, objected in the form of tools, things, language, works of art, etc. "The child should complete practical or cognitive activity in relation to them, which adequate (though not identical) to that human activity which is "objected" or "embodied" in them" (Leontyev, 1997).

In the works of L.S. Vygotskiy, P.Y. Galperin, V.V. Davydov, A.V. Zaporozhets, D.B. Elkonin and other representatives of Russian psychological school, it is intentionally shown that every time there is an objective in front of a person to acquire some material there will always be the place for some definite activities of the subject, connected with the discovery of this material characteristics and their acquisition. Another problem is that this activity can be formed spontaneously, can be realized and not realized by the child, be complete and conceptual at a different extent (Vygotskiy, 1997; Galperin, 1998; Davydov, 1986; Zaporozhets, 1986; Elkonin, 1998).

\section{Methodology}

We have designed and inculcated the program of cognitive processes development for the $2^{\text {nd }}$ grade schoolchildren. The choice of this grade out of all other classes of primary school was imposed by more relevance in the development of cognitive processes as in the $1^{\text {st }}$ grade the children are still on the stage of adaptation to school and experience overloads to which they have to adapt psychologically. Vygotskiy L.S. has introduced a very important notion for psychology "social situation of development", i.e. "the system of relationship" of the child and social environment, determining the contents and direction of this process and the formation of the central line of development, connected with basic new growth. The change of this system determines the basic law of age dynamics. According to this law driving forces of the child's development at this or that age lead to negation and destruction of the foundation of the whole age development; with inner necessity determining the annulment of social situation of the development and finishing this epoch of the development and transition to the next or higher age stage (Vygotskiy, 1984).

According to the data of the research second grade is the optimal to conduct correction development classes. All the stages of diagnostic and development work that have been realized with the $2^{\text {nd }}$ grade primary school children are reflected in Figure 1.

The program was directed at primary school children cognitive processes development. The most part of the program consists of exercises, games, techniques to develop memory, attention, verbal-logical thinking of children. The program supposes group work ( 7 - 10 people) twice a week for about 30-35 minutes before midday. Every game is "repeated" several times on different material during several classes. Correction-development activity took 4 months. During program realization the psychologist has to conduct dynamic observation of every child's progress, record research results in the protocol. This will help him to plan individual and group correction classes, directed at the development of separate psychic functions and operations (motor activity development, 
space gnosis, attention, memory, operations of analysis, comparison, generalization, etc.). Next stage is program realization of primary school children cognitive processes development according to the scheme described in Table 1.

Diagnostic module composition to determine the level of cognitive processes development

Conducting diagnostics of the level of cognitive processes development

Composing the program of primary school children cognitive processes development

Program of primary school children cognitive processes development validation

Conducting repeated test to determine efficiency of the composed program of cognitive processes development

Figure 1. The algorythm of designing and conducting the program of primary school children cognitive processes development example of a figure caption (figure caption).

Table 1. Program contents on primary school children cognitive processes development.

\begin{tabular}{|c|c|}
\hline Games and exercises name & What is development directed at \\
\hline Puzzles & $\begin{array}{l}\text { Develop image and logical thinking, the skill to single out and compare essential characteristics, } \\
\text { train quickness and flexibility of mind, agility, ability to find original solutions }\end{array}$ \\
\hline Sentences composition & $\begin{array}{l}\text { Develops verbal-logic thinking, ability to set up various links among ordinary objects, } \\
\text { creatively produce new integral images of separate isolated objects }\end{array}$ \\
\hline Excluding odd & $\begin{array}{l}\text { Develops verbal-logic thinking, ability not only to set up unexpected links among isolated } \\
\text { phenomena, but easily transfer from one link to another, without falling for it. It allows } \\
\text { simultaneously withhold in the area of thinking several objects at the same time and } \\
\text { compare them with each other }\end{array}$ \\
\hline Analogue search & $\begin{array}{l}\text { Develops verbal-logic thinking, teaches to single out in the object various characteristics } \\
\text { and operate with each of them separately, forms the ability to classify phenomena according } \\
\text { to their characteristics }\end{array}$ \\
\hline Ways of the object application & $\begin{array}{l}\text { Develops the ability to concentrate thinking on one object, the ability to introduce it in } \\
\text { different situations and interrelations, reveal unusual possibilities in an ordinary object }\end{array}$ \\
\hline General notions revelation & $\begin{array}{l}\text { Directed at generalization, revealing generic characteristics, logic links determination } \\
\text { with definite general word }\end{array}$ \\
\hline "Question game” & Ability to formulate the question, logically reason specific topics \\
\hline "Similarity and difference" & The function of comparison on essential characteristics \\
\hline “What’s new?” & Contributes to logic discussion, creativity manifestation \\
\hline “Opposite objects search” & Directed at object comparison, the search of characteristics of the object \\
\hline $\begin{array}{l}\text { "The search of objects on } \\
\text { predetermined characteristics" }\end{array}$ & Allows to find the analogues between various objects and phenomena \\
\hline "Ways of object application” & Develops the ability to concentrate on the object, ability to open unexpected possibilities in it \\
\hline "Definitions formulation” & Teaches distinct and orderliness of thinking, independence of formulations \\
\hline "List of possible reasons” & Directed at thinking breadth, in-depth analysis \\
\hline
\end{tabular}




\section{Results and Discussion}

During the first class the psychologist introduces children the first two games, provides everybody with the possibility to think, enclose his own variant of the solution. Every next class games familiar to children are played again and a new one is offered. The psychologist's objective is to encourage children's thinking activity, involve in the game those who prefer to keep silent, successively lead the thought about the fact that there is no correct solution that different answers are possible sometimes very unlike from each other.

General recommendations offered for the games:

1) You should not suppress playful answers, as they are most often a flash of thinking irregularity;

2) The psychologist has to determine "the happy medium” between the quantity and quality of the answers. On the one hand, encourage as more as possible different answers, on the other, first of all to stimulate original creative solutions.

3) Obligatory conditions of games conducting is the discussion by the children of all offered solutions and explicit substantiation, why they liked some solution and why not they did not like the other.

The third stage of realization of developing program was in conducting second check up on offered before diagnostics methods. This allowed determining how efficient was offered and approved program on cognitive processes development with primary school children development.

Table 2 presents the results repeated diagnosis with the use of $\chi^{2}$-Pearson criterion calculations.

For this selection the critical value of $\chi^{2}$-Pearson criterion is with $p \leq 0.05, \chi^{2}=5.99$, with $p \leq 0.01, \chi^{2}=$ 9.21, with degree of freedom equals to 2 . In this case it is singled out that differences are statically significant on the following scales: attention distribution $\left(\chi^{2}=6.0\right)$, attention switch $\left(\chi^{2}=6,7\right)$, attention capacity $\left(\chi^{2}=\right.$ 6.8), visual memorizing $\left(\chi^{2}=7.0\right)$, mediated memorizing $\left(\chi^{2}=7.3\right)$, memorizing $\operatorname{dynamism}\left(\chi^{2}=7.4\right)$, visual-image thinking $\left(\chi^{2}=6.3\right)$, visual-efficient thinking $\left(\chi^{2}=7.2\right)$. Thus, on this scale we can speak about the fact that there are differences in the indexes of primary and secondary check-ups on the level of $1 \%$ of differences significance.

Results, recorded in Figure 2 and Figure 3 allow speaking about the fact that after conducted development program on cognitive processes development it is clear that there is dynamics in attention processes changes. Thus if there are high results with $35 \%$ on productivity, stability and distribution while primary check-up and $45 \%$ and 65\% during secondary check-up correspondingly. High results were not found on attention switch and capacity

Table 2. The results of primary and secondary check-ups diagnostics of cognitive processes.

\begin{tabular}{|c|c|c|c|c|c|c|c|}
\hline & \multicolumn{4}{|c|}{ Primary check-ups } & \multicolumn{2}{|c|}{$\begin{array}{c}\text { Secondary check-up } \\
\text { (after development program) }\end{array}$} & \multirow[t]{2}{*}{$\begin{array}{c}\text { The meaning of } \\
\chi^{2} \text {-Pearson criterion }\end{array}$} \\
\hline & $\begin{array}{l}\text { High } \\
\text { results }\end{array}$ & $\begin{array}{l}\text { Average } \\
\text { results }\end{array}$ & $\begin{array}{l}\text { Low } \\
\text { results }\end{array}$ & $\begin{array}{l}\text { High } \\
\text { results }\end{array}$ & $\begin{array}{l}\text { Average } \\
\text { results }\end{array}$ & $\begin{array}{l}\text { Low } \\
\text { results }\end{array}$ & \\
\hline Attention productivity and stability & 35 & 65 & 0 & 45 & 55 & 0 & 3.6 \\
\hline Attention distribution & 35 & 65 & 0 & 65 & 35 & 0 & $6.0^{*}$ \\
\hline Attention switch & 0 & 30 & 70 & 35 & 35 & 30 & $6.7^{*}$ \\
\hline Attention capacity & 0 & 30 & 70 & 35 & 35 & 30 & $6.8^{*}$ \\
\hline Visual memorizing & 20 & 80 & 0 & 45 & 55 & 0 & $7.0^{*}$ \\
\hline Mediated memorizing & 15 & 85 & 0 & 45 & 55 & 0 & $7.3^{*}$ \\
\hline Memorizing dynamism & 20 & 80 & 0 & 55 & 45 & 0 & $7.4^{*}$ \\
\hline Memorizing productivity & 70 & 30 & 0 & 80 & 20 & 0 & 2.5 \\
\hline Imagination & 25 & 35 & 40 & 35 & 45 & 20 & 3.4 \\
\hline Verbal-logic thinking & 45 & 40 & 15 & 45 & 55 & 0 & 2.9 \\
\hline Visual-image thinking & 15 & 35 & 50 & 35 & 50 & 15 & $6.3^{*}$ \\
\hline Visual-efficient thinking & 15 & 45 & 40 & 45 & 40 & 15 & $7.2^{*}$ \\
\hline
\end{tabular}




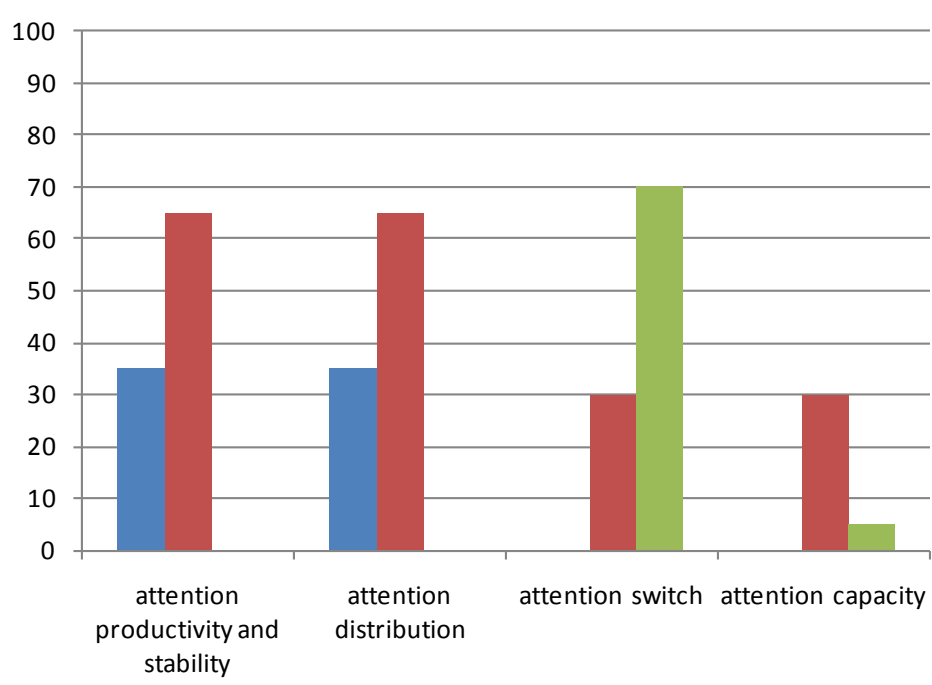

High results

Average results

Low results

Figure 2. Primary check-up results on the methods, diagnosing attention (\%).

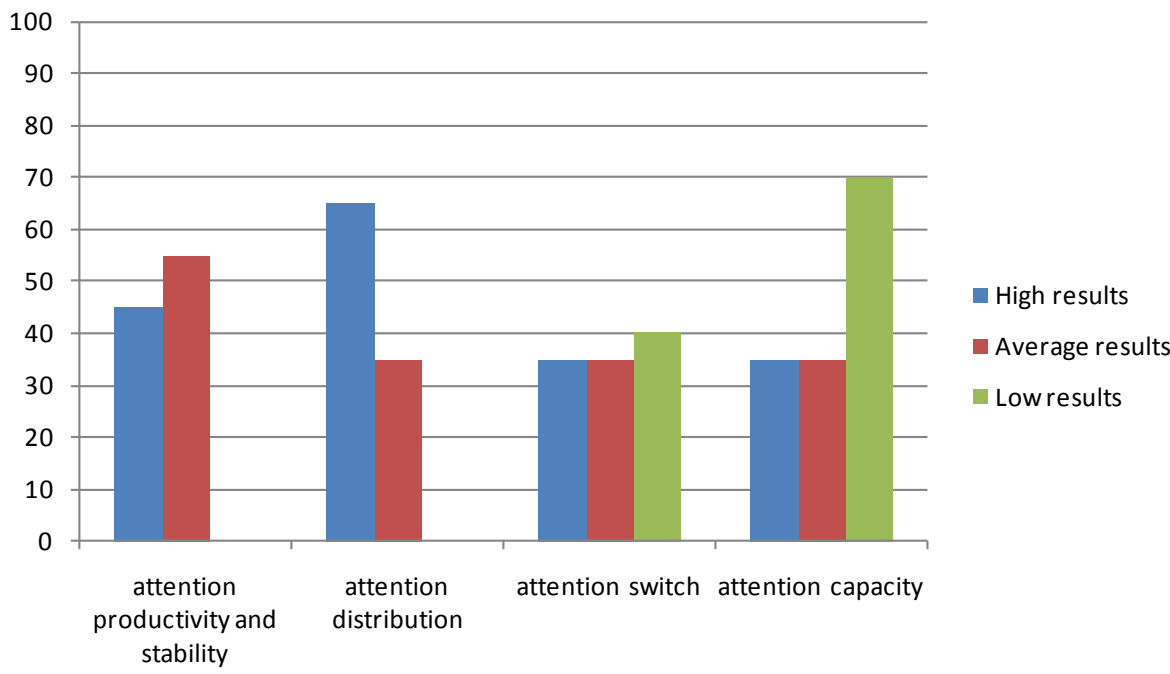

Figure 3. The results of secondary check-ups on the methods, diagnosing attention (\%).

with primary school children, whereas after program realization it prevailed with $35 \%$ of second grade primary school children.

It is necessary to point out that judging from Figure 4 and Figure 5 results have increasing tendency. According to the methods, diagnosing peculiarities of visual and mediating memorizing, memorizing dynamism and productivity it could be seen that there is an increase of the number of children demonstrating high rates after development program approbation, though average level on this retrieval still remains expressed.

If to consider dynamics change in the development of thinking processes (Figure 6 and Figure 7) here we discover that there is an increase of children number showing high results on visual-efficient (from $15 \%$ to $45 \%$ ) and visual-image (from 15 to 35 ) thinking. The same $45 \%$ of schoolchildren continue to demonstrate high rates, however there is an increase of the number of schoolchildren with average scores $55 \%$. Low results were not registered. Therefore it is possible to state that there is a slight increase of both high and average (25\% and 35\%) results. Thus, conducted research allows to state that designed and approved program on the development of cognitive processes is efficient. Increase of the number of primary schoolchildren showing high and average results and the decrease of the number of schoolchildren with low rates can be explained by the increase of the rates of apprehension, analysis, ability to act in mind, i.e. by characteristics of verbal-logic thinking, and also changes in the processes of attention and memory. 


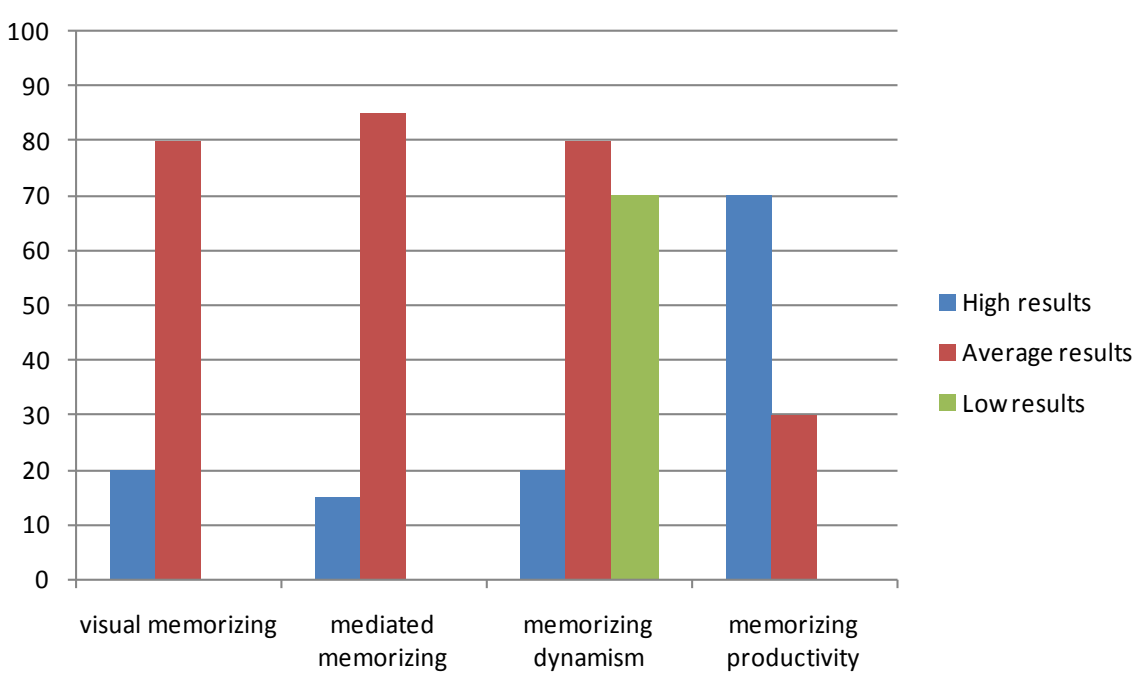

Figure 4. The results of primary check-ups on methods, diagnosing memory (\%).

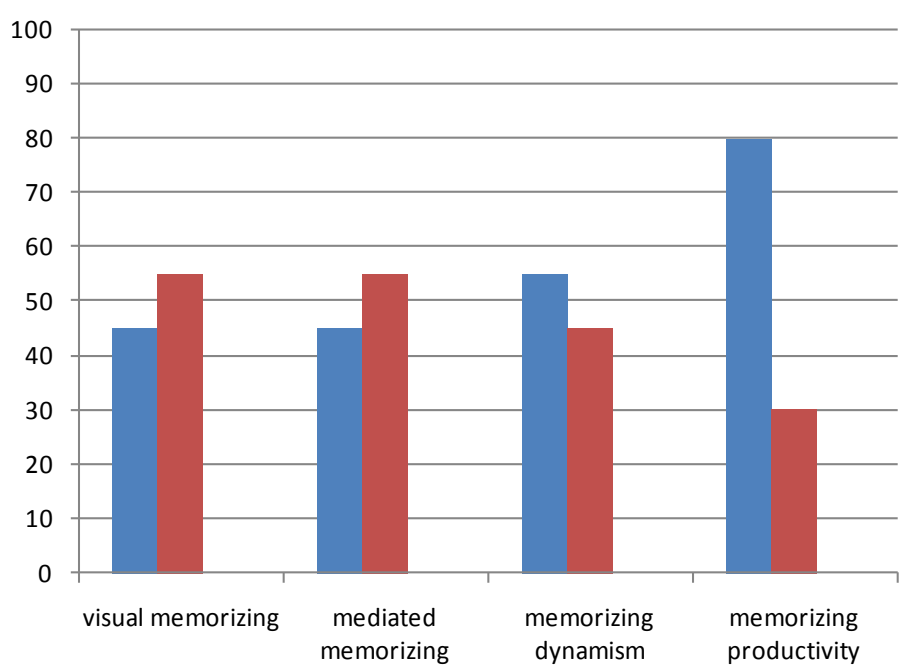

High results

Average results - Low results

Figure 5. Secondary check-up on the methods diagnosing memory (\%).

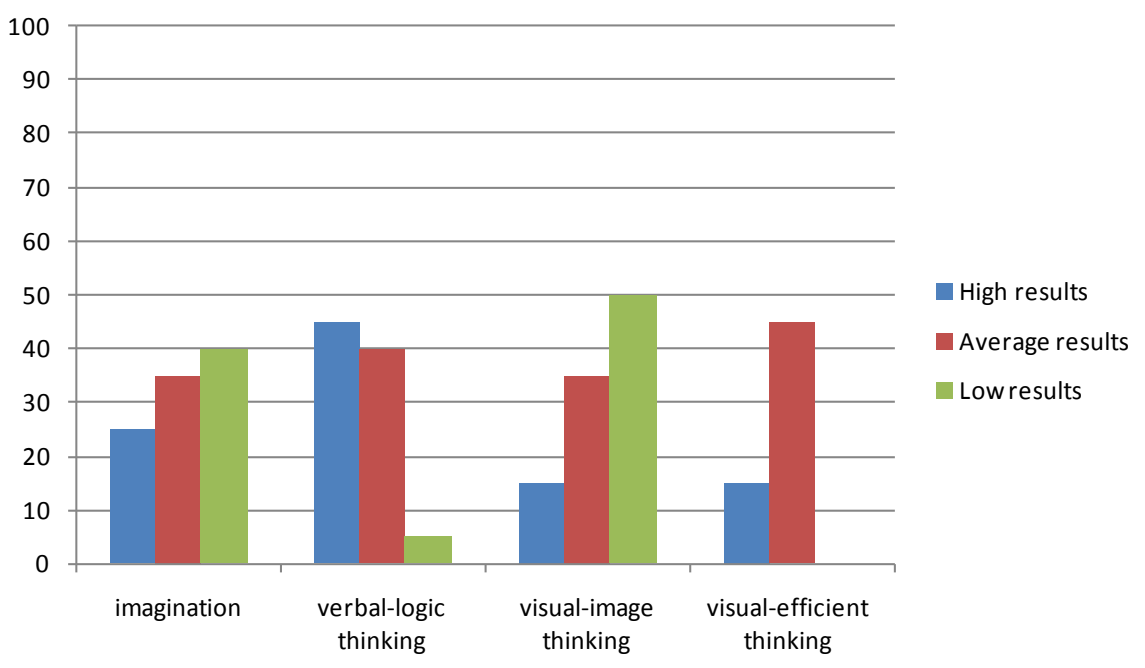

Figure 6. Primary check up results on the methods, diagnosing thinking (\%). 


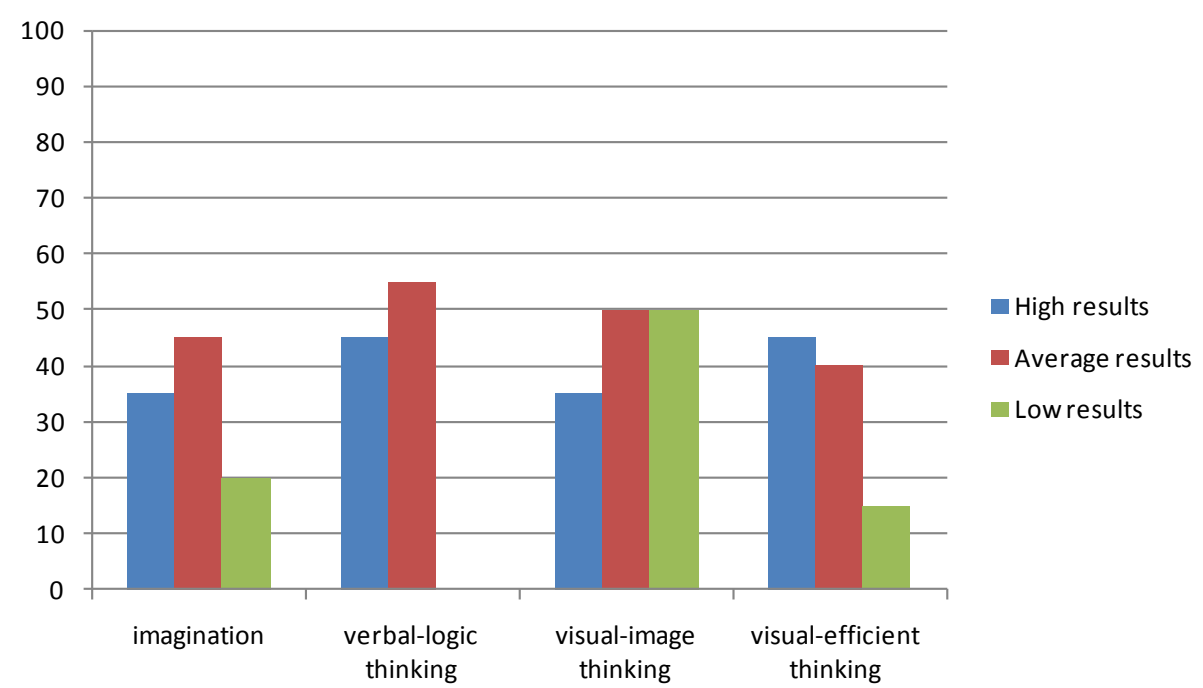

Figure 7. Secondary check-up results on the methods diagnosing thinking (\%).

\section{Conclusion}

Personality development is an infinite process of new possibilities creation, turning them into matter of fact. Age-related changes in the conditions of up-brining and teaching have decisive influence for not only psychic but also cognitive processes. Primary school children can not only acquire the ways of subjective and cognitive activities, empiric and theoretic knowledge but also be psychologically included in the education activity itself, i.e. conscientiously acquire those ways of educational activity that change and develop cognitive abilities. Primary school children are capable of developing their abilities and those personal qualities that will become the basis of cognitive processes development and as a consequence influences educational activity progress.

Primary school children cognitive processes are considered as constantly changing deep and qualitative personality characteristics, directed at consciousness of activity subject and achievement of final, significant result for him. Activity, independence, initiative and creativity are the leading factors in determining personality development in modern conditions.

\section{References}

Davydov, V. V. (1986). The Problems of Developing Education. Experience of Theoretical and Experimental Psychological Research (p. 240). Moscow: Pedagogy.

Elkonin, D. B. (1974). The Psychology of Teaching Primary Schoolchildren (p. 64). M.: Knowledge.

Elkonin, D. B. (1998). Schoolchildren Written and Oral Speech Development (p. 12). Moscow: INTOR.

Galperin, P. Y. (1998). Psychology as an Objective Science (p. 479). Selected Psychological Works.

Leontyev, A. N. (1997). About the Issue of Learning Consciousness. Psychological Science and Education, 11-15.

Vygotskiy, L. S. (1983). The Problems of Psychic Development (V. 3, p. 368). Collected Edition in 6 Volumes.

Vygotskiy, L. S. (1984). Children's Psychology (V. 6, p. 260). Collected Edition in 6 Volumes.

Vygotskiy, L. S. (1997). The Issues of Children Psychology (p. 221). St. Petersburg: Union.

Zaporozhets, A. V. (1986). Child's Psychological Development (V. 1, p. 316). Selected Psychological Works in 2 Volumes, Moscow: Pedagogy. 